\title{
Assessment for Secondary School Students' Experiences in Using Tablet in Classroom
}

\author{
Mohammed Elmetwali Mohammed Amer ${ }^{1}$ \\ ${ }^{1}$ Computer Science and Information Department, College of Science and Humanity Studies, Prince Sattam bin \\ Abdulaziz University, Al-Sulail, Saudi Arabia \\ Correspondence: Mohammed Elmetwali Mohammed Amer, Assistant professor, Computer Science and \\ Information Department, College of Science and Humanity Studies, Prince Sattam bin Abdulaziz University, \\ Al-Sulail, Saudi Arabia.
}

Received: June 8, 2020

Accepted: July 26, 2020

Online Published: August 3, 2020

doi:10.20849/jed.v4i2.782

URL: https://doi.org/10.20849/jed.v4i2.782

\begin{abstract}
The Egyptian government integrated tablets in Egyptian secondary schools. Thus, the researcher aimed to explore the effectiveness of using tablet in Egyptian secondary schools from the students' perspective. He aimed to explore that in order to assess students' experiences in this regard. He selected a random sample consisting from 745 female and male secondary school students in Egypt. Those students were selected from three schools. Questionnaire forms were distributed to those students by hand. All the distributed forms were retrieved. However, 9 forms were excluded due to missing data. Thus, 736 questionnaire forms are valid for analysis. It was found that tablet serves as an effective learning method in Egyptian secondary schools. It was found that using tablet in classroom improves students' creative thinking skills and makes teachers more creative. It was found that using tablet in classroom enriches students' vocabulary, improves their language skills and increases their academic achievement in classroom. It was found that such use can meet the learning needs of various types of learners. The researcher recommends conducting studies about the challenges facing teachers in using tablets in classroom.
\end{abstract}

Keywords: M-learning, secondary schools, Egypt, tablet, assessment, classroom

\section{Introduction}

Mobile technologies have been increasingly spreading in all countries. For instance, today, there are about 7.5 billion tablets and mobile phones in use worldwide. In addition, the increasing number of the mobile devices in use is five times bigger than the increasing number of the world population (Wilden, 2017). Mobile technologies refer to portable electronic devices, such as: personal digital assistants (PDAs), mobile phones, tablets and etc.. The use of mobile technologies in learning is called (m-learning). Due to the increasing spread of m-learning, instructors have been exerting much effort to develop their capabilities in using mobile technologies. That is because teachers want to develop themselves professionally and get promotions. Through adopting an m-learning approach, learners shall become more capable to handle many problems that are associated with the learning process (Al-Tamimi, 2017). Adopting such an approach shall improve students' learning outcomes (Al-Zahrani and Laxman, 2015).

In this regard, it should be noted that tablet has been increasingly used for learning and teaching in academic institutions, such as: schools, and universities. That applies to developing and developed countries (Quniebi, 2016). Tablet is used today in various academic institutions to meet the learning needs of the $21^{\text {st }}$ century students (Algoufi, 2016). It has been increasingly used by students for messaging their peers and instructors, browsing internet pages, playing educational games and learning new information (Arshad, and Ali, 2017). Today, many schools in developing countries - e.g. Egypt- introduced tablets into school classrooms as an attempt to improve the quality of the delivered education. For taking this step, the Egyptian government started distributing tablet packages on 11/2/2019 to the first group of the first secondary grade students in private and public schools. Tablets were also distributed to teachers. Later on, other tablet packages were distributed by the Egyptian government to other groups of students through following a specific schedule. Before taking this step, the Egyptian government provided classrooms with smart boards and improved the IT infrastructure of schools (Hussein, 2019). 
The Egyptian government introduced tablets in secondary education in order to provide students with access to online information. That is needed in the light of the increasing amount of digital knowledge. The model of the distributed tablet by the Egyptian government is Samsung T585. When submitting the tablet package to the student, the student and his/her parent must sign a paper acknowledging that they have received this package. This package includes the tablet device itself and its cover, pen, charger, and earphone (Hussein, 2019). The use of tablets in classroom has made a transformation in the way of delivering information. That is because students and teachers will not have to use paper, pencil, nor the conventional black boards any more. The use of tablets in classroom has made a transformation in the way of assigning tasks and distributing worksheets. For instance, it enables teachers to distribute worksheets online to students instead of distributing them by hand. It enables teachers to illustrate information multimedia and sound and motion effects instead of illustrating it verbally. That turns the learning process into a fun process (Quniebi, 2016). The use of tablets in classroom made a transformation in the way of searching for information. Instead of searching for information among numerous papers, students and teachers shall become capable of navigating the internet fast and easily to search for the sought information (Quniebi, 2016).

There is an increasing interest in using iPad in classroom for many reasons. For instance, tablets can be easily used. They can be easily carried and moved from one place to another. The use of tablet participates in increasing students' concentration and enables learners to learn faster. It makes learning enjoyable and fun rather than dull and boring (Hart, \& Laher, 2019). It enables students and teachers to move freely in classroom, because tablets are lighter than PCs and aren't connected with wires to a source of electric power. It enables students to access online information instantly. It enables students and teachers to interact with experts and other people. It facilitates the processes of storing, retrieving and sharing information in a wireless manner. Through using tablets, teachers shall become capable of updating material (Hashim et al., 2016)

However, there are challenges associated with integrating tablets in secondary education in Egypt. For instance, there must be a developed IT infrastructure. Security breaches may occur and a tablet may get lost or stolen. In addition, teachers and students must be provided with training courses of high quality about the way of using tablet. There must be also special curricula that fit with such an integration (Hashim et al., 2016). In the light of the merits and challenges of using tablet in classroom, the researcher of this study believes that it is necessary to explore the effectiveness of using tablet in secondary schools in Egypt from the students' perspective. Therefore, the researcher aimed to explore such effectiveness through conducting the present study. Exploring such effectiveness shall contribute in improving the quality of secondary education in Egypt.

\section{Objectives}

This study aimed to:

a)- Assess the skills of the students enrolled at secondary schools in Egypt in using tablet

b)- Identify the effectiveness of using tablet in secondary schools in Egypt from the students' perspective.

\section{Questions}

This study aims to answer the following questions:

a)- How are the skills of the students enrolled at secondary schools in Egypt in using tablet?

b)- How effective are tablets in secondary schools in Egypt from the students' perspective?

\section{Significance of the Study}

The present study is significant due to the scarcity of the studies that address this subject. It is significant because it is useful for:

a- Officials at the Egyptian Ministry of Education: This study shall enable those officials to identify the capabilities of secondary school students in Egypt in using tablets. Identifying that is needed after integrating tablets in secondary education in Egypt. It enables those officials to identify the amount of training that must be provided for secondary school students need about the way of using tablets. This study shall provide those officials with information about the effectiveness of using tablets in secondary schools in Egypt. The latter information shall enable those officials to make decisions on whether to integrate tablets in other school stages, such as: the elementary or the preparatory school stage.

b- Policy makers in Egypt: The results of this study shall enable policy makers in Egypt to develop effective policies for improving the quality of school education 
c- Researchers: This study shall enrich the empirical literature of the researchers who want to conduct research about tablets and m-learning. It provides those researchers with a research instrument.

d- Trainers: This study shall promote knowledge among trainers about the benefits of m-learning. That shall positively affect the quality of their training courses.

\section{Limits}

The present study was conducted during the first semester of the academic year (2019/2020). It was conducted in several Egyptian secondary schools.

\section{Definition of Terms}

-M-learning: It refers to the use of portable electronic devices in the learning process, such as: personal digital assistants (PDAs), mobile phones, tablets and etc.. (Al-Tamimi, 2017)

-Tablet: It's an ICT device which size is bigger than a smartphone and smaller than a laptop. It doesn't require using a mouse or a keyboard. It enables people to search for knowledge, read books, watch movies and etc... (Algoufi, 2016)

\section{Theoretical Framework}

Having a tablet in classroom enables teachers to meet the learning needs of many types of students. For instance, it meets the learning of visual learners through providing them with educational videos and images about the topic they are learning about. It meets the learning needs of auditory learners. For instance, it provides auditory learners with auditory materials (e.g. voice record) (Schnackenberg, 2013). It should be noted that tablets can be effectively used for teaching disabled students. Such use shall effectively improve the engagement of disabled students in the teaching-learning process. It shall increase the independence of disabled students in the classroom (Wiley et al., 2014). It shall make learning more organized. It shall promote learner-autonomy. It shall promote a purposive learning approach. However, the barriers facing such use must be addressed to improve the learning process. Such barriers may include technical barriers (Butcher, 2014)

Through using a tablet, students shall become the managers of their own learning process. They shall become more capable to manage their time effectively. Using a tablet enables students to examine their current knowledge and discover new knowledge. It enables students to interact with instructors and students in various countries through eliminating the spatial barriers (Algoufi, 2016).

When using mobile technologies -like tablets- in classroom, teachers and students will not have to use the conventional blackboard anymore. That shall save the effort of students and teachers. Using mobile technologies in classroom enables students to organize files, and edit, copy \& paste texts. It enables teachers to carry out various types of instructional activities in classroom. It enables learners and teachers to simulate the real environment and draw maps and diagrams. It increases students' engagement in the learning process. That's because mobile technologies offer students many educational games that aim at enriching their knowledge and improving their capabilities. It meets the students' learning needs and enables students' to access the required material at any place and time. It facilitates the cooperation between students (Hashim et al., 2016).

Using mobile technologies -like tablet- in learning enables students to move freely and search for information fast. It enables students to access images, scientific designs, graphs, audio files, and tables (Hashim et al., 2016). It allows students to take photos, play games, send messages, record audio files, and surf the internet for specific information. It encourages students to speak up in classroom in front of others. It can be used to enhance the $21^{\text {st }}$ century skills of students. Those skills are: (collaboration, communication, creativity and critical thinking skills) (Wilden, 2017).

The use of mobile technologies -like tablet- in learning can improve students' digital literacy. Digital literacy refers to the extent of possessing the social and individual skills needed for using various digital devices. Improving students' digital literacy shall improve their skills in searching for online information. The use of mobile technologies -like tablet- in learning enriches students' factual knowledge. It enables students to store their works and share them. It facilitates the way of distributing an educational material -e.g. corrected exams and worksheets- to students. For instance, the teacher can save a worksheet on Dropbox or iCloud in order for all the students in class to access it through their devices (Wilden, 2017).

The use of mobile technologies -like tablet- in learning improves students' real life communication and offers students opportunities to practice language. It enables students to assess their language competency by themselves. It makes students control and manage their own learning by themselves. It enables students to access visual dictionaries and electronic books. The use of mobile technologies -like tablet- in classroom enables 
teachers to adopt a digital storytelling approach. Digital storytelling refers to the use of digital devices for telling a story, along with displaying texts, images, audio files and etc.. It improves students' knowledge about narrative tenses and increases their engagement, because it offers them opportunities to work in groups. It offers students the capability to express their ideas and learn from their peers (Wilden, 2017).

The use of mobile technologies -like tablet- in classroom is effective for learning medical sciences. It participates in enriching students' theoretical knowledge. It raises students' levels of confidence and clinical competency. It improves students' skills and positively affects their interests, attitudes and values. It increases students' satisfaction with the quality of the learning process (Koohestani et al., 2018). Mobile technologies may be used for assessment. Such use positively affects students' performance level and attitudes. It motivates students to show the best performance (Nikou, and Economides, 2018). It should be noted that tablets can be effectively used for teaching the ones with learning disabilities, such as: slow learners. Such use can motivate slow learners to learn and promote collaboration among them. It can increase the attention and confidence levels of slow learners and make learning enjoyable for them (Hassan and Mahmud, 2018)

\section{Empirical Literature}

The researcher presented below several empirical studies which are arranged based on the year of publication (i.e. from the oldest ones to the latest ones):

Montrieux et al. (2015) aimed to explore the attitudes of students towards using tablet in the process of learning. They conducted interviews to collect data. The sample consists from 18 school teachers and 39 secondary school students. They found that that using tablets provide media-rich, interactive and exciting new environments. In addition, students and teachers have positive attitude towards such use. The teachers' perceptions for the use of tablets affect their teaching practice.

Nawi et al. (2015) aimed to explore the attitudes of teachers in Putrajaya, Selangor towards the use of mobile technologies for teaching Islamic education course. The sample consists from 32 teachers who teach Islamic education course. A questionnaire was used. It was found that teachers have positive attitudes towards using mobile technologies for teaching Islamic education course. It was found that respondents are willing to use mobile technologies in this course.

Wang et al. (2015) aimed to explore university students' attitudes towards using iPad in classroom in Taiwan. They also aimed to explore the effectiveness of using iPad in learning vocabulary. An experimental approach was adopted and a questionnaire was used. Pre-test and post-test were used. It was found that using iPad is effective for learning language. It was found that using iPad enriches students' vocabulary, and improves students' outcomes \& academic achievement. It was found that using iPad doesn't make students like the course they are taking. It was found that using iPad doesn't make students feel more confident about their learning capabilities. It was found that using iPad makes students spend less time when learning something. It was found that using iPad doesn't increase students' motivation to learn. It was found that using iPad promotes autonomy in learning and encourages students to review the lesson at home. It was found that using iPad increases students' academic achievement.

Quniebi (2016) aimed to explore the effectiveness of using iPad in the learning process in classroom in Jordan. She used two questionnaires and conducted several interviews. A questionnaire was used to collect data from 55 teachers and another one was used to collect data from 143 students. Those students were selected from $8^{\text {th }}, 10^{\text {th }}$ and $9^{\text {th }}$ grades. Interviews were conducted with 18 teachers. Through using the teacher's questionnaire, it was found that iPad presents the academic material in an interesting manner and enables teachers to take notes effectively. It was found that using iPad application promotes autonomy in learning. It was found that iPad is a secure learning method that is difficult to attack by viruses. Through using the students' questionnaire, it was found that using iPad facilitates the communication between the teacher and students. Through conducting the interviews, it was found that using iPad plays an effective role in saving teachers' time and efforts. It was found that using iPad makes learning fun instead of being dull and boring. It was found that iPad motivates students to learn and facilitates the illustration of concepts and information due to the presence of multimedia features. It was found that using iPad shall make the illustrated information unforgettable.

Arshad and Ali (2017) aimed to explore the attitudes of school students in Egypt towards m-learning. They used a questionnaire and the SPSS program/ version No.23. The sample consists from 120 students who were selected from a public preparatory school in Egypt. It was found that m-learning is characterized with flexibility and being enjoyable. It was found that m-learning enables students to learn independently, increases their academic achievement levels and enriches their knowledge. It was found that m-learning increases the communication 
between teachers and students. However, there are barriers associated with adopting an m-learning approach, such as: the need to charge batteries.

Alzaidiyeen (2017) aimed to explore EFL students' attitudes towards the use of iPad in learning English language in Saudi Arabia. He used a questionnaire for data collection. The sample consists from $109 \mathrm{EFL}$ students enrolled at Majmmah University in Saudi Arabia. ANOVA and t-test were conducted and frequencies, and percentages were calculated. It was found that there isn't any significant difference between the respondents' attitudes which can be attributed to gender, age or academic level. It was found that using iPad improves students' language skills and assists them in doing assignments. It was found that using iPad enables students to get information fast and organize their works. It was found that respondent desire to learn more information about the way of using iPad.

Erkir et al. (2017) aimed to explore the attitudes of teachers and faculty members towards using tablet in the language teaching process. The sample consists from 143 faculty members and teachers. SPSS and Microsoft Excel were used. It was found that using tablet in classroom shall make teachers more creative and more organized. It was found that using tablet improves the interaction between instructors and student and increases students' participation in classroom. It was found that using tablet improves students' learning experiences, and encourages them to learn and search for more information about the topic they are learning about.

Al-Tamimi (2017) aimed to explore the attitudes of Arabic language teachers towards mobile learning in Dhi Qar, Iraq. The sample consists from 82 teachers; 50 males and 32 females. A descriptive approach was adopted and a questionnaire was developed and used. It was found that m-learning enables teachers to retrieve information fast and easily and present the material in an interesting manner. It was found that m-learning increases students' interaction with one another in the classroom. It was found that m-learning makes teachers more creative in the classroom and facilitates the way of delivering and illustrating information. It was found that m-learning improves students' creative thinking skills and reduces the shyness associated with the learning process.

Semerci (2018) aimed to explore the attitudes of high school students towards using tablets in education. The sample consists from 16 high school students. Data was collected through conducting interviews. It was found that students have positive attitudes towards using tablets. In addition, using tablets positively affects the student-student interaction and the student-teacher interaction. It provides students with digital bookstores and access to many books, and notebooks. Thus, it spares students from carrying heavy schoolbags. It offers students enjoyable learning experiences and enables students to solve problems quickly. However, it affects students' attention during class because it includes several games.

Al-Tamimi and Abed Al-Hadi (2018) aimed to explore the attitudes of primary school students in Jordan towards using IPAD in learning. They aimed to explore the impact of using IPAD on the acquisition of religious terms. They used a questionnaire to explore the respondents' attitudes. They used pre-test and post-test to explore the impact of IPAD on such acquisition. The sample consists from 87 students. It was found that using IPAD has a statistically significant positive impact on the acquisition of religious terms. In addition, students have positive attitudes towards using ipad. Such use makes learning enjoyable and promotes positive attitudes towards school. It encourages students to read more books, do homework, and take notes.

Quniebi (2019) aimed to develop a proposed model for integrating tablet into classroom in Jordan. She conducted interviews with 18 teachers and $288^{\text {th }}, 10^{\text {th }}$ and $9^{\text {th }}$ grade students. Those students and teachers were selected purposively from Al-Hasasd School in Jordan. The selected students use tablets at classroom. The proposed model consists from several stages; planning, preparation \& development, implementation, assessment and following-up stages. Through conducting interviews with teachers, it was found that integrating tablets into classroom in requires developing and training teachers and activating control and security guard programs. Such integration requires preventing students from uploading non-educational games and accessing inappropriate websites. It also requires developing the IT infrastructure and addressing the technical problems. It requires providing maintenance services in an ongoing manner. It requires providing interactive books and academic games and applications, including applications in Arabic language. It requires making IT-related departments in school and setting effective plans. Through conducting interviews with students, it was found that such integration requires training students about the way of using iPad and providing them with access to internet during classes (Quniebi, 2019). 


\section{Methodology}

\subsection{Approach}

The researcher adopted a descriptive analytical approach.

\subsection{Methods for Data Collection}

To obtain the needed data from the members of the sample, a questionnaire was used. To enrich the study's theoretical framework and empirical literature, several books, newspaper articles, and studies were reviewed.

\subsection{Population and Sample}

The study's population consists from all the female and male secondary school students in Egypt. Based on the study of Singh, and Masuku, (2014), if the members of the population are greater than 100,000 members, the sample should be consisting from 400 members at least. Complying with such rules shall ensure having accurate results. The researcher selected a random sample consisting from 745 female and male secondary school students in Egypt. Those students are selected from the first secondary grade in three public schools located in Dekernes, Dakahlia. These schools are: Hussein Hammad Secondary School for Girls, Al-Hadeetha Secondary School for Girls and Um-Almu'alimeen Secondary School for boys. All of the sampled students use tablets in classroom. Questionnaire forms were distributed to those secondary school students by hand. All these forms were filled and retrieved. However, 9 forms were excluded due to having missing data. Thus, 736 questionnaire forms are valid for analysis.

Table 1 presents the gender of the respondents. It can be noticed that $25.71 \%$ of the respondents are males, whereas $74.72 \%$ of the respondents are females.

Table 1. Gender of the respondents

\begin{tabular}{llll}
\hline Variable & Category & Frequency & Percentage\% \\
\hline Gender & Male & 186 & 25.271 \\
\cline { 2 - 4 } & Female & 550 & 74.728 \\
\hline
\end{tabular}

$\mathrm{N}=73 \overline{6}$

\subsection{Instrument}

The researcher adopted the five point Likert scale. He used a questionnaire that consists from two parts. The first part aims to assess the skills of the students enrolled at secondary schools in Egypt in using tablet. The second part aims to explore the effectiveness of using tablet in secondary schools in Egypt from the students' perspective. It consists from sixteen (16) statements. It was developed based on the studies conducted by: Wang et al. (2015), Erkir et al. (2017), Alzaidiyeen (2017), Arshad and Ali (2017), Hart, \& Laher (2019), Quniebi (2016), Hashim et al. (2016), Al-Tamimi (2017), and Schnackenberg (2013). Through the cover page of the questionnaire, the researcher informed the members of the sample that the collected data shall be considered confidential. The questionnaire forms were distributed in Arabic language to the sample and panel of experts to assess it. However, it was translated into English language later.

\subsection{Validity}

To check the validity of the questionnaire, the researcher passed the preliminary version of the questionnaire to 2 faculty members. Those faculty members work in Saudi universities, and specialized in educational sciences. The researcher asked those faculty members to provide an evaluation for the preliminary version of the questionnaire. Such evaluation must be made in terms of language, relevancy and clarity. Both faculty members suggested that the questionnaire doesn't include any language mistake. They suggested that the questionnaire is capable of meeting the study's objectives. They added that the questionnaire's items are clear. However, one of the faculty members recommended deleting one statement. Such deletion was made. After that, the final version of the questionnaire was developed by the researcher.

\subsection{Reliability}

The researcher calculated the Cronbach alpha coefficient value. It's 0.851 . That means that the questionnaire is very reliable. It also means that the results obtained through the questionnaire are reliable and accurate. 


\subsection{Statistical Analysis and Criteria}

To analyze the data that was obtained through the questionnaire, the researcher calculated standard deviations and means. To measure reliability, Cronbach alpha was calculated too. For classifying means, specific criteria were adopted by the researcher. These criteria are displayed through the table presented below.

Table 2. The criteria that are used by the researcher for classifying means

\begin{tabular}{lll}
\hline Range & Level & Attitude \\
\hline 2.33 or less & Low & Negative attitude \\
\hline $2.34-3.66$ & Moderate & Neutral attitude \\
\hline 3.67 or more & High & Positive attitude \\
\hline
\end{tabular}

Source: Al-Amery (2020)

Regarding the five point Likert scale, it consists from five (5) rating categories. Those categories are displayed through the table below. Each category represents a specific score.

Table 3. The categories and scores of the five point Likert scale

\begin{tabular}{llllll}
\hline Category & Strongly agree & Agree & Neutral & Disagree & Strongly disagree \\
\hline The score it represents & 5 & 4 & 3 & 2 & 1 \\
\hline
\end{tabular}

Source: Al-Amery (2020)

\section{Discussion and Results}

\subsection{Discussion and Results Related to the First Question}

Q.1: How are the skills of the students enrolled at secondary schools in Egypt in using tablet?

Table 4. The skills of the students enrolled at secondary schools in Egypt in using tablet

\begin{tabular}{llll}
\hline Question & Category & Frequency & Percentage\% \\
\hline $\begin{array}{l}\text { How do you assess your } \\
\text { skills in using tablet? }\end{array}$ & Excellent & 29 & 3.940 \\
\cline { 2 - 4 } & very good & 53 & 7.201 \\
\cline { 2 - 4 } & Good & 146 & 19.836 \\
\cline { 2 - 4 } & Fair & 384 & 52.173 \\
\cline { 2 - 4 } & Poor & 124 & 16.847 \\
\hline
\end{tabular}

$\mathrm{N}=7 \overline{36}$

Percentages and frequencies are calculated to assess the skills of the students enrolled at secondary schools in Egypt in using tablet. It was found that 3.94\% of the respondents have excellent skills in using tablet and $7.20 \%$ of the respondents have very good skills in using tablet. It was found that $19.83 \%$ of the respondents have good skills in using tablet. It was found that $52.17 \%$ of the respondents have fair skills in using tablet and $16.84 \%$ of the respondents have poor skills in using tablet. That means that secondary school students in Egypt are in need for receiving training courses about the way of using tablet. Providing students with such courses shall enable them to utilize tablet effectively in classroom.

\subsection{Discussion and Results Related to the Second Question}

Q.2: How effective are tablets in secondary schools in Egypt from the students' perspective?

Table 5 presents data about the effectiveness of using tablet. 
Table 5. The effectiveness of using tablet in secondary schools in Egypt from the students' perspective

\begin{tabular}{|c|c|c|c|c|c|}
\hline No. & Statement & Mean & Std. & Attitude & Level \\
\hline 1. & Using iPad in classroom shall increase students' vocabulary & 4.91 & 0.27 & Positive & High \\
\hline 2. & $\begin{array}{l}\text { Using iPad in classroom shall increase students' motivation to } \\
\text { learn about the topic illustrated by the teacher }\end{array}$ & 2.01 & 0.45 & Negative & Low \\
\hline 3. & $\begin{array}{l}\text { Using iPad in classroom shall increase students' participation } \\
\text { in classroom }\end{array}$ & 4.84 & 0.53 & Positive & High \\
\hline 4. & $\begin{array}{l}\text { Using iPad in classroom shall make students like the course } \\
\text { they are taking }\end{array}$ & 2.27 & 0.16 & Negative & Low \\
\hline 5. & $\begin{array}{l}\text { Using iPad in classroom is effective for improving students' } \\
\text { language skills }\end{array}$ & 4.63 & 0.58 & Positive & High \\
\hline 6. & $\begin{array}{l}\text { Using iPad in classroom shall improve the interaction between } \\
\text { instructor and students in classroom }\end{array}$ & 4.27 & 0.89 & Positive & High \\
\hline 7. & $\begin{array}{l}\text { Using iPad in classroom shall make students spend less time } \\
\text { when learning something }\end{array}$ & 2.94 & 0.62 & Negative & Low \\
\hline 8. & $\begin{array}{l}\text { Using iPad in classroom shall increase students' academic } \\
\text { achievement }\end{array}$ & 4.47 & 0.37 & Positive & High \\
\hline 9. & Using iPad in classroom shall make learning fun and enjoyable & 4.82 & 0.60 & Positive & High \\
\hline 10. & $\begin{array}{l}\text { Using iPad in classroom shall make the illustrated information } \\
\text { unforgettable }\end{array}$ & 2.31 & 0.42 & Negative & Low \\
\hline 11. & Using iPad in classroom shall save teachers' effort & 4.52 & 0.29 & Positive & High \\
\hline 12. & Using iPad in classroom shall make teachers more creative & 4.65 & 0.51 & Positive & High \\
\hline 13. & $\begin{array}{l}\text { Using iPad in classroom shall improve students' creative } \\
\text { thinking skills }\end{array}$ & 4.93 & 0.73 & Positive & High \\
\hline 14. & Using iPad in classroom shall make teachers more organized & 2.12 & 0.64 & Negative & Low \\
\hline 15. & $\begin{array}{l}\text { Using iPad in classroom shall reduce the shyness associated } \\
\text { with the learning process }\end{array}$ & 4.80 & 0.71 & Positive & High \\
\hline \multirow[t]{2}{*}{16.} & $\begin{array}{l}\text { Using iPad in classroom shall meet the learning needs of } \\
\text { various types of learners }\end{array}$ & 4.74 & 0.95 & Positive & High \\
\hline & Total & 3.95 & 0.54 & Positive & High \\
\hline
\end{tabular}

It was found that using tablet in secondary schools in Egypt is effective from the students' perspective. That means that the experience of Egyptian secondary school students is using tablet are positive. That is because the total mean is 3.95. It was found that using iPad in classroom doesn't increase students' motivation to learn about the topic illustrated by the teacher, because the relevant mean is 2.01 . The latter result is consistent with the result concluded by Wang et al. (2015). It may be attributed to the fact that motivating students is affected mainly by the use of rewards and positive words for encouragement. It was found that using iPad in classroom increases students' participation in classroom, because the relevant mean is 4.84 . The latter result is consistent with the result concluded by Erkir et al. (2017).

It was found that using iPad in classroom shall not necessarily make students like the course they are taking, because the relevant mean is 2.94 . The latter result is consistent with the result concluded by Wang et al. (2015). It was found that using iPad in classroom is effective for improving students' language skills, because the relevant mean is 4.63. The latter result is consistent with the result concluded by Alzaidiyeen (2017). It is attributed to the fact that tablet enables students to acquire much knowledge about language and interact with native speakers in various countries. It was found that using iPad in classroom improves the interaction between instructors and student in classroom, because the relevant mean is 4.27 . The latter result is consistent with the result concluded by Erkir et al. (2017).

It was found that using iPad in classroom doesn't make students spend less time when learning something, because the relevant mean is 2.94. The latter result is consistent with the result concluded by Wang et al. (2015). It may be attributed to the fact that the amount of time needed for learning depends on students' IQ level and the strategy adopted by the teacher. It was found that using iPad in classroom increases students' academic 
achievement, because the relevant mean is 4.47 . The latter result is consistent with the result concluded by Arshad and Ali (2017). That may be attributed to the fact that tablet enables students to see practical applications of knowledge which shall improve their understanding.

It was found that using iPad in classroom makes learning fun and enjoyable, because the relevant mean is 4.82 . The latter result is consistent with the result concluded by Hart, \& Laher (2019). It may be attributed to the fact that tablet enables teachers to carry out various activities and use educational games in classroom. It was found that using iPad in classroom doesn't make the illustrated information unforgettable, because the relevant mean is 2.31. The latter result is inconsistent with the result concluded by Quniebi (2016). It may be attributed to the fact that students may forget the illustrated information after a long period of time in case they don't revise it.

It was found that using iPad in classroom saves teachers' effort, because the relevant mean is 4.52 . The latter result is inconsistent with the result suggested by Hashim et al. (2016). It may be attributed to the fact that teachers will not have to distribute papers by hand anymore nor use a pen to write on board when having tablets. It was found that using iPad in classroom makes teachers more creative because the relevant mean is 4.65 . The latter result is consistent with the result concluded by Al-Tamimi (2017). It may be attributed to the fact that tablet provides teachers with many special features, such as: multimedia, educational games and etc.. The presence of such features enables teachers to show creativity in the way of delivering information.

It was found that using iPad in classroom improves students' creative thinking skills, because the relevant mean is 4.93. The latter result is consistent with the result concluded by Al-Tamimi (2017). It may be attributed to the fact that tablet enables students to see places that are difficult or costly to visit and watch dangerous experiments conducted by others. It was found that using iPad in classroom doesn't make teachers more organized, because the relevant mean is 2.12. The latter result is inconsistent with the result concluded by Erkir et al. (2017). That's because a teacher may have all the technological devices without being organized.

It was found that using iPad in classroom reduces the shyness associated with the learning process, because the relevant mean is 4.80. The latter result is consistent with the result concluded by Al-Tamimi (2017). It may be attributed to the fact that tablet provides students with the ability to participate in activities that doesn't require talking much in front of the students. It was found that using iPad in classroom meets the learning needs of various types of learners, because the relevant mean is 4.74 . The latter result is consistent with what's suggested by Schnackenberg (2013). It may be attributed to the fact that tablet is suitable for auditory and visual learners and the ones who learn through text-based instruction. It may be attributed to the fact tablet is suitable for the learners who suffer from auditory and visual impairments

\section{Conclusion}

The Egyptian government integrated tablets in Egyptian secondary schools. That was done in order to make reforms to the Egyptian education sector, keep up with the latest technologies and meet the modern academic needs of students. This step shall pave the way towards adopting other types of learning in Egyptian schools, such as: virtual learning. The researcher believes that such type of learning must be available for the students who request it. That's because there are disabled students, and students in hospitals and prisons who are in need for adopting a virtual learning approach. However, that requires making major costly developments to the IT infrastructure in Egypt.

It was found that using tablet in secondary schools in Egypt is effective from the students' perspective. It was found that the experiences of Egyptian secondary school students in using tablet are positive. It was found that using tablet in classroom enriches students' vocabulary, improves their language skills and increases their academic achievement and participation in classroom. It was found that using tablet in classroom improve the interaction between instructor and students in classroom and save teachers' effort. However, using iPad in classroom doesn't increase students' motivation to learn about the topic illustrated by the teachers. It shall not necessarily make students like the course they are taking

The researcher of this study believes that tablets should be used in all educational institutions in Egypt instead of using paper-based curricula and notebooks. That shall spare students from carrying heavy bags as it is suggested by Semerci (2018). That shall positively affect students' physical health in schools and universities. That is because heavy bags negatively affect students' back and bone development. In addition, tablets should be used in all educational institutions in Egypt because such use shall provide students with access to numerous books in classroom as it's suggested by Semerci (2018). That shall enable educational institutions in Egypt to save the costs incurred for buying paper-based books. 
Similar to Hassan and Mahmud (2018) and Wiley et al. (2014), the researcher of this study believe that tablets should be used in the special educational institutions in Egypt. That shall enhance the quality of the education provided for those students. It shall enable empower those student and enable them to work and support themselves in the future. The researchers of the present study believe that studies must explore teachers' attitude towards using tablets in Egyptian schools. That's because such attitudes shall affect teachers' practices in classroom as it's suggested by Montrieux et al. (2015)

\section{Recommendations}

The researcher recommends:

a- Providing each secondary school that use tablets with IT department for providing support to teachers and students.

b- Using tablets in primary schools in Egypt.

c- Providing secondary school teachers and students with training courses about the way of using tablets.

d- Conducting studies about the challenges facing teachers in using tablets in classroom.

e- Conducting studies about the effectiveness of using other mobile technologies in secondary classroom, such as smartphones.

\section{Acknowledgment}

The researcher would like to thank the Egyptian Ministry of Education for exerting much effort to improve education.

\section{References}

Al-Amery, A. (2020) Attitudes of the students at the institutes of fine arts in Iraq towards implementing active learning strategies in Arabic language courses and the associated challenges. Journal of Education and Practice, 11(13). https://doi.org/10.7176/JEP/11-13-08

Algoufi, R. (2016). Using Tablet on Education. World Journal of Education, 6(3), 113-119.

Al-Tamimi, E., \& Abed Al-Hadi, S. (2018). The impact of the use of the IPAD and its applications on the collection of some religious concepts among primary school students in Jordan and their attitudes towards its use. International Journal of Educational Psychological Studies, 2(3), 369-394. Retrieved from https://www.refaad.com/views/EPSR/233.html

Al-Tamimi, R. (2017). Effectiveness of the Arabic language teachers in the use of mobile learning and other educational stages. Journal of Human Sciences, 2(24), 1115-1134. Retrieved from https://www.iasj.net/iasj?func=article\&aId=138838

Al-Zahrani, H., \& Laxman, K. (2015). A critical meta-analysis of mobile learning research in higher education. Journal of Technology Studies, 41(2), 74-89.

Alzaidiyeen, N. (2017). English as a foreign language students attitudes towards the utilization of iPad in language learning. Malaysian Online Journal of Educational Technology, 5(3), 16-24.

Arshad, M., \& Ali, R. (2017). Investigating the perception of students regarding MLearning concept in Egyptian schools. International Journal of Interactive Mobile Technologies (iJIM), 11(6), 112-122.

Butcher, J. (2014). Can tablet computers enhance learning in further education?. Journal of Further and Higher Education, 40(2), 207-226.

Erkir, S., Kayapinar, U., \& Köse, N. (2017). Attitudes towards tablet use in language teaching. Journal of Education and Practice, 8, 16-20.

Hart, S., \& Laher, S. (2019). The role that access and attitudes toward tablets have on learners' achievement in a Johannesburg school. South African Journal of Education, 39(3), 1-11.

Hashim, Y., Osman, A., \& El-Gelany, A. (2016). Mobile technology and education: theoretical study. International Research Journal of Computer Science (IRJCS), 2(3), 16-27.

Hassan, A., \& Mahmud, M. (2018). Learning motivation for slow learners with tablet technology. International Journal for Studies on Children, Women, Elderly and Disabled, 5.

Hussein, M. (2019). The distribution of tablets to the first grade of secondary education in 20 cities. Alyoum Alsabe $\quad$ Electronic Newspaper. $\quad$ Retrieved from https://www.youm7.com/story/2019/2/11/\%D8\%AA\%D9\%88\%D8\%B2\%D9\%8A\%D8\%B9-\%D8\%A7\%D 9\%84\%D8\%AA\%D8\%A7\%D8\%A8\%D9\%84\%D8\%AA-\%D8\%B9\%D9\%84\%D9\%89-\%D8\%B7\%D9\%8 
4\%D8\%A7\%D8\%A8-\%D8\%A3\%D9\%88\%D9\%84\%D9\%89-\%D8\%AB\%D8\%A7\%D9\%86\%D9\%88\%D 9\%89-\%D9\%81\%D9\%89-20-\%D9\%85\%D8\%AD\%D8\%A7\%D9\%81\%D8\%B8\%D8\%A9/4136578

Koohestani, H. R., Soltani Arabshahi, S. K., Fata, L., \& Ahmadi, F. (2018). The educational effects of mobile learning on students of medical sciences: A systematic review in experimental studies. Journal of Advances in Medical Education \& Professionalism, 6(2), 58-69.

Montrieux, H., Vanderlinde, R., Schellens, T., \& De Marez, L. (2015). Teaching and learning with mobile technology: A qualitative explorative study about the introduction of tablet devices in secondary education. PloS One, 10(12), e0144008. https://doi.org/10.1371/journal.pone.0144008

Nawi, A., Hamzah, M., \& Abdul Rahim, A. (2015). Teacher acceptance of mobile learning for teaching and learning in Islamic education: a preliminary study. Journal Turkish Online Journal of Distance Education, $19(1)$.

Nikou, S., \& Economides, E. (2018). Mobile-based assessment: A literature review of publications in major referred journals from 2009 to 2018. Computers \& Education, 125, 101-119.

Quniebi, F. (2016). Evaluation of using iPad in classroom learning and teaching. International Journal of Education and Research, 4(6), 169-186.

Quniebi, F. (2019). Developing a proposed model for introducing tablet PC it in teaching learning process. Dirasat Journal: Educational Sciences, 1(1), 377-396. Retrieved from https://dirasat.ju.edu.jo/ES/Article/FullText/12989?volume=46\&issue=1

Schnackenberg, H. (2013). Tablet technologies and education. International Journal of Education and Practice, $1(4), 44-50$.

Semerci, A. (2018). Students' views on the use of tablet computers in education. World Journal on Educational Technology: Current Issues, 10(2), 104-114.

Singh, A., \& Masuku, M. (2014). Sampling techniques and determination of sampling size in applied statistics research: An overview. International Journal of Economics, Commerce and Management, 2(11).

Wang, B., Teng, C., \& Chen, H. (2015). Using iPad to facilitate English vocabulary learning. International Journal of Information and Education Technology, 5(2).

Wilden, S. (2017). Mobile learning: Into the classroom (1st ed.). United Kingdom. Oxford University Press. Retrieved from https://books.google.jo/books?id=fFQ0DwAAQBAJ\&source=gbs_navlinks_s

Wiley, B., Cameron, D., Gulati, S., \& Hogg, A. (2014). Exploring the use of tablets (iPads) with children and young adults with disabilities in Trinidad. Disability and rehabilitation. Assistive Technology, 11(1), 32-37.

\section{Appendixes}

Appendix A

Images for the distribution of tablet packages to the first group of 1st secondary grade students in Egypt.

The images below shows the distribution of tablet packages to the first group of $1^{\text {st }}$ secondary grade students in Egypt (Hussein, 2019).

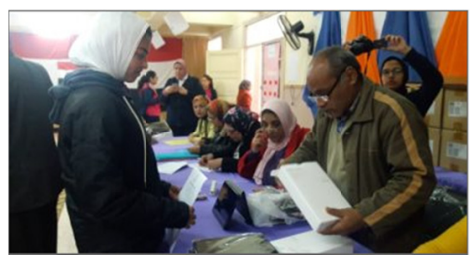

Figure 1

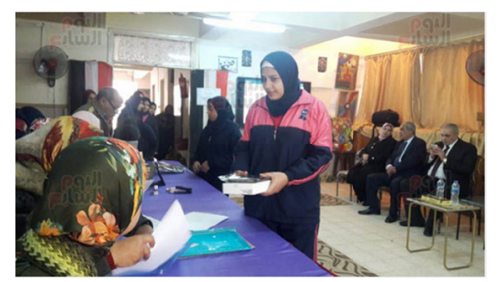

Figure 2 


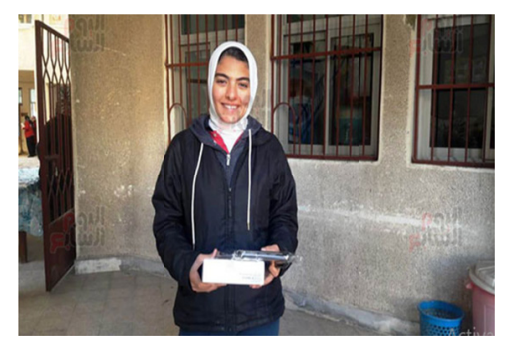

Figure 3

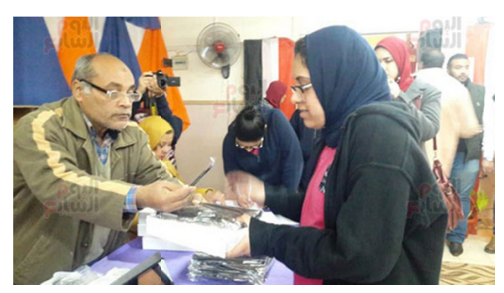

Figure 4

\section{Appendix B}

The number of tablets that were distributed for the first time to the1st secondary grade students in Egypt

Table 6. The number of tablets that were distributed for the first time to the1st secondary grade students in Egypt

\begin{tabular}{lll}
\hline No. & Area & Number of the distributed tablets in the area \\
\hline 1. & Al-Ismaileye & 7919 \\
\hline 2. & Bour Said & 5682 \\
\hline 3. & Al-Suwais & 4075 \\
\hline 4. & Marsa Matrouh & 1863 \\
\hline 5. & North Sinah & 3300 \\
\hline 6. & Al-Wadi Al-Jadid & 2601 \\
\hline 7. & Al-Uqur & 6349 \\
\hline 8. & South Sinah & 832 \\
\hline 9. & Al-Bahr Al-Ahmar & 2885 \\
\hline 10. & Aswan & 7289 \\
\hline 11. & Al-Fayoom & 14841 \\
\hline 12. & Bani Swaif & 16643 \\
\hline 13. & Waqna & 16353 \\
\hline 14. & Alexandria & 45349 \\
\hline 15. & Cairo & 91572 \\
\hline 16. & Almina & 29854 \\
\hline 17. & Asyoot & 24801 \\
\hline 18. & Suhaj & 21137 \\
\hline 19. & Alsharqeye & 50017 \\
\hline 20. & Dumyat & 12585 \\
\hline
\end{tabular}

*Source: Hussein (2019)

\section{Copyrights}

Copyright for this article is retained by the author(s), with first publication rights granted to the journal. This is an open-access article distributed under the terms and conditions of the Creative Commons Attribution license (http://creativecommons.org/licenses/by/4.0/). 